\title{
Erratum to: Brief histories of medical physics in Asia-Oceania
}

\author{
W. H. Round ${ }^{1}$ - S. Jafari ${ }^{2}$ - T. Kron ${ }^{3}$ - H. A. Azhari ${ }^{4}$ - S. Chhom ${ }^{5}$. \\ Y. $\mathrm{Hu}^{6} \cdot$ G. F. Mauldon ${ }^{7}$ K. Y. Y. Cheung ${ }^{8}$ - T. Kuppusamy9 $~$ S. A. Pawiro ${ }^{10}$. \\ L. E. Lubis ${ }^{10}$ - D. S. Soejoko ${ }^{10}$ - F. Haryanto ${ }^{10}$ - M. Endo ${ }^{11}$ - Y. Han ${ }^{12}$. \\ T. S. Suh ${ }^{13}$ - K. H. $\mathrm{Ng}^{14}$ - A. Luvsan-Ish ${ }^{15}$ - S. O. Maung ${ }^{16}$ - P. P. Chaurasia ${ }^{17}$.

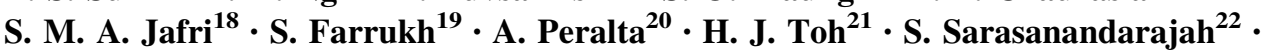

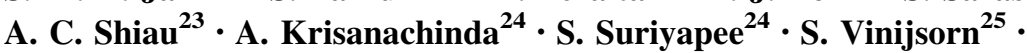 \\ T. C. Nguyen ${ }^{26}$
}

Received: 1 April 2015/Accepted: 10 July 2015/Published online: 8 September 2015

(C) Australasian College of Physical Scientists and Engineers in Medicine 2015

\section{Erratum to: Australas Phys Eng Sci Med DOI 10.1007/s13246-015-0342-9}

The review entitled Brief histories of medical physics in Asia-Oceania published online 28 August 2015, replaces the version that was previously published online 18 April
2015. The latest version has been accepted for publication by the editors and will be used for publication in the online and printed issue.

The online version of the original article can be found under doi:10.1007/s13246-015-0342-9.

W. H. Round

h.round@waikato.ac.nz

1 School of Engineering, University of Waikato, Private Bag 3105, Hamilton 3240, New Zealand

2 Kabul Medical University, Kabul, Afghanistan

3 Peter MacCallum Institute, Melbourne, Australia

4 Department of Medical Physics and Biomedical Engineering, Gono Bishwabidyalay, Dhaka, Bangladesh

5 Calmette Hospital, Phnom Penh, Cambodia

6 Cancer Institute, CAMS, Beijing, People's Republic of China

7 Queen Elizabeth Hospital, Kowloon, Hong Kong

8 Hong Kong Sanatorium \& Hospital, Wan Chai, Hong Kong

9 Medical Physics Division, Dr. Kamakshi Memorial Hospital, Chennai, India

10 Physics Department, University of Indonesia, Depok, Indonesia

11 Ion Beam Therapy Center, SAGA HIMAT Foundation, Tosu, Japan

12 SamSungkyunkwan University School of Medicine, Seoul, Korea
13 The Catholic University of Korea, Seoul, Korea

14 University of Malaya Medical Centre, Kuala Lumpur, Malaysia

15 Mongolian National University of Medical Sciences, Ulaanbaatar, Mongolia

16 Yangon General Hospital, Yangon, Myanmar

17 B.P. Koirala Memorial Cancer Hospital, Bharatpur, Nepal

18 Pakistan National Regulatory Authority, Islamabad, Pakistan

19 Jinnah Postgraduate Medical Centre, Karachi, Pakistan

20 Department of Health, Manila, Philippines

21 Radiation Oncology Centre, Mount Elizabeth Hospital, Singapore, Singapore

22 Peter MacCallum Cancer Institute, Melbourne, Australia

23 Department of Medical Physics, Koo Foundation Sun YatSen Cancer Center Hospital, Taipei, Taiwan

24 Chulalongkorn University, Bangkok, Thailand

25 Siriraj Hospital, Mahidol University, Bangkok, Thailand

26 Unit of PET-CT and Cyclotron, Choray Hospital, Ho Chi Minh City, Vietnam 